\title{
Comments
}

Pharmacology

\section{Making the Case for 'Power Abuse Disorder' as a Nosologic Entity}

\author{
Gerald Zernig ${ }^{a} \quad$ Christoph Hiemke ${ }^{b}$ \\ ${ }^{a}$ Experimental Psychiatry Unit, Department of Psychiatry 1, Medical University of Innsbruck, Innsbruck, Austria; \\ ${ }^{b}$ Department of Psychiatry and Psychotherapy, University Medical Center Mainz, Mainz, Germany
}

\section{Keywords}

Power abuse disorder - Cocaine - Social interaction .

Dependence syndrome · Burnout

\begin{abstract}
The development of societies and cultures arguably is based on the ability of human primates to form hierarchies in which some individuals acquire and wield power, that is, control resources and influence and control the behavior of their conspecifics. In the following, we focus on the type of human primate power wielding that (a) harms and (b) produces excessive negative emotions in (1) the victim(s) of the power wielder and (2) the power wielder her/himself. If such a harmful behavior of the power wielder is not accompanied by an ethically justifiable benefit for the involved human primate groups, it can be considered "power abuse." We propose to term the associated behaviors, cognitions, and emotions of the power wielder as "power abuse disorder" (PAD). This behavior results from what we consider addictive behavior of the power abuse disordered (PADed) power wielder. PAD can be diagnosed on the basis of the World Health Organization's criteria for "dependence syndrome" as listed in the International Classification of Diseases version 10. We will demonstrate that many PADed individuals may very likely carry the Zeitgeist diagnosis "burnout." This article reviews
\end{abstract}

\begin{tabular}{ll}
\hline KARGER & $\begin{array}{l}\text { (c) } 2017 \text { The Author(s) } \\
\text { Published by S. Karger AG, Basel Oparger }\end{array}$ \\
E-Mail karger@karger.com & \\
www.karger.com/pha & $\begin{array}{l}\text { This article is licensed under the Creative Commons Attribution- } \\
\text { NonCommercial-NoDerivatives 4.0 International License (CC BY- } \\
\text { NC-ND) (http://www.karger.com/Services/OpenAccessLicense). } \\
\text { Usage and distribution for commercial purposes as well as any dis- } \\
\text { tribution of modified material requires written permission. }\end{array}$
\end{tabular}

the current understanding of the neural correlates of PAD and suggests future research. Based on the available evidence, PAD seems to be associated with a dysfunction of the mesocorticolimbic dopamine system, rendering PADed individuals vulnerable for psychostimulant abuse/dependence, and suggesting specific pharmacotherapeutic approaches to treat PAD.

\author{
(C) 2017 The Author(s) \\ Published by S. Karger AG, Basel
}

\section{Introduction}

The development of societies and cultural achievements is arguably based on the ability of humans (i.e., human primates) to form hierarchies, in which some individuals acquire and wield power, that is, control limited resources and influence and/or control the behavior of their conspecifics. An animal experimental operationalization of social dominance with very high face validity for our (i.e., human primate) minds is winning a fight [1-10]. Maybe of even higher impact for the evolutionary selection process, dominance can be seen and has been operationalized as competitive control over access to vital resources such as water [11], food [12], space for advancement in its literal sense [11], or access to avoidance of unpleasant/harmful stimuli [12], which are 
all helpful for the survival of the individual, and for its control over reproduction within a group $[7,13,14]$, which in turn is beneficial for the spread of such an individual's genes.

But are the neurobiologic mechanisms underlying the fight of two mice over a scrap of leftover cheese comparable to the travails of 21st-century Woman striving toward self-realization in a professional career? We will show in the following that they are. For one, we human primates are able to covet objects at such a degree of abstraction that the visual presentation of status symbols like luxury cars [15] or even the expectation of a monetary reward [16], with money arguably being one of the most salient status symbols, is able to activate the same neurocircuits (i.e., the so-called reward pathways) that are activated by "natural" or "physiologic" reinforcers (such as food, water, or sex) in rodents or nonhuman primates, in particular a brain region that is central to motivated behavior, that is, the nucleus acumbens (called "ventral striatum" in human imaging studies; see, e.g., $[10,17-23])$. To paraphrase, the same neuronetworks that mediate motivated behavior for "natural" or "physiologic" rewards (e.g., food, water, sex) are also involved in drug seeking and consumption, that is, measures of substance dependence, in all species mentioned above. Not only is the seeking and consumption of physiologic reinforcers and drugs of abuse mediated by the same neuronetworks: the non-drug addictive disorder "pathological gambling" (code F63.0) of the International Classification of Diseases version 10 (ICD10) [24], which is essentially identical to the "gambling disorder" (code 312.31) of the Diagnostic and Statistical Manual 5th edition (DSMV, DSM5) of the American Psychiatric Association [25], is considered to involve essentially the same neurocircuits as the seeking and consumption of drugs of abuse, having prompted clinical trials in which the same medications that had been evaluated for the treatment of substance dependence syndromes/substance-use disorders were tested for their effectiveness against gambling disorder [26]. By the same token, we think that the nondrug addictive disorder proposed here, power abuse disorder (PAD), shares the same neurobiologic basis as well. Another nonpharmacologic stimulus that may engender addictive behavior, internet gaming, is already on its way to be incorporated into mental disorder compendia, as evidenced by its inclusion as a "condition for further study" in the DSM5 [25]. To emphasize, any motivated behavior, including food seeking and consumption [27], carries the risk of becoming addictive, with the nucleus accumbens (see, e.g., $[10,17-23]$ ) and,

Power Abuse Disorder possibly, the whole accumbens corridor $[10,28,29]$ as the central neuroanatomic hot spot of the motivational neuronetwork (reward pathways) and dopamine as the major neurotransmitter driving motivated behavior. Interestingly, food and power share the paradox of being both essential for our survival as well as becoming extremely harmful for us if abused.

We all have experienced that losing control over a resource to another conspecific is associated with negative emotions, an experience we share with other species, for example, rodents. However, even in the absence of competition for resources, social dominance (an alternative term for "power wielding") significantly decreases the attractiveness of dyadic social interaction for the subordinate animal, even if the likely hierarchic difference is modest, that is, only consists of a maximum of 2 -fold weight difference during 4 consecutive 15 -min dyadic social encounters between otherwise singly housed male rats [30]. There is a plethora of animal studies demonstrating that social dominance, at least in despotic species/genus like nonhuman primates, rats, or mice [31], can actually be harmful for the subordinate individual $[13,14,31]$. Even in humans, the constant proximity to an anxiety-provoking dominant member of one's own species, with dominance being maintained in despotic species through repeated intimidation rather than fullblown aggression, results in dendritic atrophy, impaired neurogenesis and synaptic plasticity, enhanced GABAA receptor antagonist-inducible anxiety ("enhanced endogenous benzodiazepine tone" [32]), elevated basal levels of glucocorticoids, sluggish response to and recovery from stress, basal immunosuppression and decreased immune responsiveness to challenge, basal hypertension, a pathologic cholesterol profile, testicular atrophy, decreased gonadal hormones, and increased risk of anovulation and miscarriage [31].

In the following, we focus on the type of human primate power wielding that (a) harms and (b) produces excessive negative emotions in (1) the subordinate(s) of a socially dominant individual and (2) the power wielder her/himself. By "excessive negative emotions" we mean negative emotions of an intensity that exceed what an average empathic observer would expect under the circumstances. If such a harmful behavior of the power wielder is not at least accompanied by an ethically justifiable benefit (see our suggestions for appropriate diagnostic settings below) for the involved human primate groups, it can be considered "power abuse." We propose to term the associated behaviors, cognitions, and emotions of the power wielder PAD. This behavior results from what we

Pharmacology 2017;100:50-63 DOI: $10.1159 / 000475600$ 
consider addictive behavior of the power abuse disordered (PADed) power wielder. PAD can thus be diagnosed according to the World Health Organization's criteria for "dependence syndrome" as listed in the ICD10 [24]. A detailed description of the ICD10-based PAD symptoms is given below.

Mirroring the behavioral similarity of PAD and other abuse/dependence syndromes, $\mathrm{PAD}$, a non-substance addictive disorder, should have a considerable number of neuroanatomic and neurobiologic commonalities with drug abuse and drug dependence (substance abuse disorders). This article discusses data on power wielding-induced changes in the dopamine system because we think that the dopamine neuronetwork is heavily affected by both substance-dependence syndromes (especially by psychostimulant use disorders) and PAD. A discussion of other involved neurotransmitter systems, unfortunately, is beyond the scope of the present article. The translational power of possible animal models of PAD will be discussed. Suggestions for future research will be given.

It should also be borne in mind that this article focuses on the less severe forms of PAD, which are well known to essentially all of us and have caused all of us discomfort and, possibly, harm. It is beyond the scope of the present article to discuss severe forms of PAD, for example, torture or the actions of power wielders in totalitarian political systems.

\section{The Clinical Presentation of PAD: Suggested Diagnostic Criteria}

At the level of human primate behavior, PAD fulfils all classic diagnostic criteria of a dependence syndrome according to the ICD10 issued by the World Health Organization (www.who.org).

The ICD10's diagnostic guidelines (http://www.who. int/substance_abuse/terminology/definition $1 /$ en/, accessed March 29, 2017; symptom numbering by the authors) are given below in the left column of the Box 1 , while the corresponding symptoms of PAD as suggested in the present article can be found in the right column.

\section{Additional Behavioral Symptoms of PAD}

PAD is characterized by behavioral symptoms that have not been covered by the ICD10 criteria for dependence syndrome, symptoms that can be helpful for a better diagnosis of $\mathrm{PAD}$, and should be the focus of future clinical research because they present targets for developing coping strategies for the victims of PAD superiors (PADS) as well as therapeutic interventions for the PADS themselves. The following behavioral symptoms of PADed power wielders are just a tiny (albeit highly relevant) sample of the symptoms that have anecdotally been observed by us:

a. A characteristic pattern of communication consisting of indirect, vague, noncommittal and/or explicitly threatening verbal and nonverbal behavior leading to fears, hopes, and confusion in the subordinate, ultimately harming the victim and sabotaging the victim's productivity.

b. Resistance by the PADed power wielder to any form of objectifiable documentation of her/his interaction with her/his victim, for example, video or audio recordings.

c. Resistance by the PADed power wielder to any form of communication that may reduce her/his perceived power, for example, team supervision. This resistance may also be in the form of apparent acceptance of the subordinate's suggestions and/or demands followed by sabotaging them.

\section{Diagnosing PAD}

So how can we arrive at a diagnosis of PAD? In everyday clinical practice, the diagnosis could be made by a trained and hopefully intervised and/or supervised professional using the diagnostic criteria detailed above. For research purposes, we suggest that a case of research interest in an anonymized form be submitted to a panel of at least 10 persons who explicitly must NOT belong to the same societal/institutional/professional system in which a putative PAD incident has occurred. Such a panel must be composed, in equal parts, of women and men and, preferably, have members from all walks of life. For a definite diagnosis of PAD, 8 of 10 panelists (i.e., 80\%) or more must come to such a conclusion. For a definite diagnosis of the absence of $\mathrm{PAD}, 8$ of 10 panelists must vote accordingly. We base the " 8 of 10 votes" requirement on Fisher's exact test (Prism 7, www.graphpad.com), which states that an 8-to- 2 vote vs. a 2-to-8 vote for a PAD diagnosis is statistically significant ( $p=0.023,2$-sided). A 4-to-1 vs. 1-4 vote, that is, a smaller panel, would not have the necessary statistical power ( $p=0.21,2$-sided). Our proposal is, of course, arbitrary and debatable, and should be tailored to the statistical needs of the respective scientific investigation.
Zernig/Hiemke 
Box 1.

ICD10 dependence syndrome

A definite diagnosis of dependence should usually be made only if three or more of the following have been present together at some time during the previous year:

1. A strong desire or sense of compulsion to take the substance
Power abuse disorder (PAD)

A definite diagnosis of PAD should usually be made only if three or more of the following have been present together at some time during the previous year:

1. A strong desire or sense of compulsion achieve and hold a position within a hierarchy that allows the holder to influence and control the behavior of subordinate(s), which is harmful for and associated with negative emotions of the subordinate(s)

2. Difficulties in controlling substance-taking behavior in terms of its onset, termination, or levels of use

2. Difficulties in controlling power-wielding behavior in terms of its onset, termination, or levels of wielding

3. A physiological withdrawal state when substance use has ceased or have been reduced, as evidenced by: the characteristic withdrawal syndrome for the substance; or use of the same (or closely related) substance with the intention of relieving or avoiding withdrawal symptoms

4. Evidence of tolerance, such that increased doses of the psychoactive substance are required in order to achieve effects originally produced by lower doses (clear examples of this are found in alcohol- and opiate-dependent individuals who may take daily doses sufficient to incapacitate or kill nontolerant users)

5. Progressive neglect of alternative pleasures or interests because of psychoactive substance use, increased amount of time necessary to obtain or take the substance or to recover from its effects

6. Persisting with substance use despite clear evidence of overtly harmful consequences, such as harm to the liver through excessive drinking, depressive mood states consequent to periods of heavy substance use, or drug-related impairment of cognitive functioning; efforts should be made to determine that the user was actually, or could be expected to be, aware of the nature and extent of the harm
3. A physiological withdrawal state when power has ceased or has been reduced, as evidenced by: the characteristic power-withdrawal syndrome; or use of the other forms of power with the intention of relieving or avoiding withdrawal symptoms

4. Evidence of tolerance, such that increased levels of power are required in order to achieve effects originally produced by lower levels

\section{Progressive neglect of alternative pleasures or interests because of power use, increased amount of time necessary to obtain or wield power or to recover from its effects}

6. Persisting with power wielding despite clear evidence of overtly harmful consequences; efforts should be made to determine that the user was actually, or could be expected to be, aware of the nature and extent of the harm. Of note, the harm is not limited to the power-dependent individual but includes and is most likely more severe for the subordinate and the environment of the PADed individual
Why has PAD not been diagnosed before? Why is the clinical and basic science literature on PAD so scarce? We opine that there is considerable political resistance to subject power wielding individuals to scientific scrutiny. From the psychotherapeutic perspective, power wielders, especially PADed ones, must be considered extremely defensive about the negative symptoms of PAD because they most likely interpret these symptoms a sign of their "weakness" and believe that any mentioning of these symptoms may threaten their dominant position. We will 
show below that many PADed individuals may very likely carry the Zeitgeist diagnosis "burnout" (PubMed, accessed on March 30, 2017, searching for "burnout" or "burn out" or "burn-out" and year of publication: 1990, 221 hits vs. 2016, 1,279 hits). The diagnosis "burnout" (see, e.g., [33-41]) has become largely socially sanctioned and culturally mainstream, removing some of the stigma attached to mental disorders, maybe even carrying, in some subcultures, an honorable connotation like the Japanese "karoshi" (from the English "crash," signifying "overwork death"). Interestingly, karoshi (see, e.g., [42, 43]) may also be a consequence of power struggles within a commercial institution and may, in some cases, be predominantly due to PAD.

\section{Treating PAD}

To emphasize, helping the victims of PADed individuals should be the first therapeutic priority, prevention and inhibitory interventions being the second. To effectively cope with PADed superiors, various techniques from a host of psychotherapeutic approaches (see, e.g., [44-46]) may be introduced to and trained with a PAD victim. It is to be expected that a PADed superior will not seek help during most of her/his disease progression (see above and below). Still, the third priority should be to offer her/him therapeutic assistance during abstinence/withdrawal ("Entzug" in German) and rehabilitation ("Entwoehnung"). At the societal level, raising awareness for PAD should help both victims and PADed superiors.

Labeling any individually and/or socially harmful behavior as a disorder/disease runs the risk of putting an individual emitting such a behavior beyond the reach of ethics and justice. To emphasize, PAD results in harmful behavior for which the individual emitting PAD-associated behavior should take full responsibility. We hope that PAD will evolve the same way as smoking did over the last 7 decades, from being perceived as an annoying yet unavoidable behavioral variant to a behavior that has been recognized as harmful for its victims and has therefore been socially sanctioned in many instances.

\section{Animal Behavioral Experimental and Neural Correlates of Power Wielding}

If, as discussed above, power wielding ("social dominance" or "dominance" for short) is a stimulus that has abuse liability, it should engage the same neuronetworks and neurotransmitter systems that drugs of abuse act upon. We will demonstrate in the following that it does. As we think that striving for and wielding power engages the dopamine system more than any other neurotransmitter systems of the reward neuronetworks (see below), we focus on the experimental evidence presented by 2 groups who not only studied the effects of power wielding on the dopaminergic system with the reward neuronetwork per se but also investigated the effects of power wielding on the consumption of cocaine, a psychostimulant; psychostimulants having been used since World War II by military personnel of various nations to boost flagging-motivated behavior and alertness (see, e.g., [47, 48]).

\section{Power Wielding Increases Accumbal D2/D3 Receptor Density}

Dopamine D2/D3 receptor density/availability was shown to increase between $+6 \%$ and $+22 \%$ in the basal ganglia, including the nucleus accumbens, of socially dominant cynomolgous monkeys (macaca fascicularis) as compared to their subordinate conspecifics, both in males [3] and females [8]. This difference between dominant and subordinate conspecifics appeared only as the hierarchy developed $[3,8]$ and disappeared again when the hierarchy was dissolved by single housing [8]. Dominant male Lister Hooded rats (females were not tested) showed a mean increase of $+19 \%$ (range, +6 to $+28 \%$ ) in D2/D3 receptor density in the left and right nucleus accumbens core and shell than subordinate animals when tested after a hierarchy had developed [11].

Interestingly, upon repeated testing of male cynomolgous monkeys in the intravenous (i.v.) cocaine self-administration paradigm, the difference in $\mathrm{D} 2 / \mathrm{D} 3$ receptor availability between dominant and subordinate conspecifics disappeared [49], suggesting that voluntary consumption of cocaine counteracts the individually beneficial effect of power wielding with respect to the sensitivity for motivationally relevant stimuli.

\section{Behavioral Consequences of a Power Wielding-Induced Increase in Accumbal D2/D3 Receptors}

What are the behavioral consequences of a power wielding-induced increase in accumbal/striatal D2/D3 receptors? The pervasive role of accumbal dopamine (see,
54

Pharmacology 2017;100:50-63

DOI: $10.1159 / 000475600$
Zernig/Hiemke 
e.g., $[10,17-23])$ for motivated behavior (as opposed to the valence of the reinforcer, and to the contribution of dopamine to the attraction/aversiveness of a stimulus) is important for our neurochemic investigation of $\mathrm{PAD}$, as the life of a PADed individual seems to be controlled more frequently and more pervasively by an escalation of their motivation to obtain power and avoid the loss of power than by actually enjoying power.

As recently as 2016, that is, 4 decades after the discovery that administration of drugs of abuse increases accumbal dopamine $[17,50]$, subsequent generations of researchers humbly concluded [51] that "overall, the role of dopamine in motivation is still considered to be mysterious," quoting the title of a 2012 review of a different group [23]. However, a crude summary seems permissible: dopamine in the accumbens is currently thought to serve at least 2 functions: (1) baseline dopamine and slow, that is, minute-to-minute, changes in accumbal dopamine (tonic DA release) seem to correlate with motivational vigor, reward rate, motivational vigor, and deprivation, whereas (2) fast, that is, second-to-second, changes in DA dopamine (phasic release) encode reward intensity/value as demonstrated by combinations of the most recent techniques [51-54].

Accumbal dopamine release [55] and accumbal activation [22] are induced by a plethora of stimuli that are considered attractive/pleasurable, including drugs of abuse like cocaine [18], which in fact, through its inhibition of dopamine reuptake, increases dopamine in the accumbens by itself and can be used to overcome a slump in motivated behavior. Cocaine is therefore a very useful experimental tool because it is both a pharmacologic probe to test the sensitivity of a power-wielding individual to attractive stimuli but also an abused drug, allowing researchers to investigate if PAD is associated with cocaine abuse/dependence (i.e., if PAD and cocaine use disorder are comorbid) or if power wielding protects against a cocaine-dependence syndrome and may even render the individual to be more appreciative of nondrug stimuli.

Some researchers (e.g., [22]) suggest that accumbal activation is exclusively associated with attractive/pleasurable/rewarding/reinforcing stimuli, whereas other researchers have pointed out that aversive stimuli and conditioning per se also lead to accumbal dopamine release and accumbal activation [56, 57]. This is important for our discussion of the neurobiologic basis of PAD because we think that the expected loss of power (be it real or imagined) is highly aversive to a PADed individual, and consequently, a major motivator for him/her through the use of the dopamine system.

Power Abuse Disorder
To conclude our brief overview of the current hypotheses regarding the role of the dopamine system (1) in motivated behavior, that is, in the seeking of attractive stimuli or avoidance of aversive stimuli; and (2) consummation/consumption of coveted stimuli, some researchers emphasize that accumbal activation can be separated into signaling a dopamine-independent "hedonic impact" or "liking" of a stimulus and signaling its "motivational salience," that is, the "wanting" such an attractive/appetitive/positively reinforcing stimulus elicits, in a dopamine-dependent manner [27]. For an illustration of the psychologic constructs involved in explaining "reward" and "reinforcement," the reader is referred to [21]. To complicate matters, recent research indicates that stimulation of accumbal medium spiny neurons expressing predominantly dopamine D2 receptors (D2-MSNs) is aversive [58] and decreases cocaine reward [59]. Employing designer receptors exclusively activated by designer drugs, it was demonstrated that D1-MSNs are necessary for the acquisition of cocaine-conditioned place preference (CPP), with D1-MSN activity peaking immediately before the mice entered the cocaine-associated compartment, whereas D2-MSN activity decreased once the mice entered the compartment [53]. In a similar vein, accumbal dopamine was shown to decline once a food reward was obtained in an operant task [51]. Others demonstrated that accumbal D1 receptor activation was necessary only for neural excitation by relevant (reward-predicting) stimuli, whereas D2 receptor activation was necessary for both reward-predicting and neutral stimuli [52]. To summarize, the above-cited experimental also indicates that both aversive and attractive aspects of stimuli are mediated by the accumbal dopamine neuronetwork, albeit by different subsystems.

On pharmacologic principle [21, 60-64], an increase in receptor density should render an individual more sensitive to the effects of agonist ligands binding to these receptors. This phenomenon has been amply demonstrated for mu opioid receptors and several behavioral paradigms, that is, self-administration of the full mu opioid receptor agonist alfentanil and the partial mu opioid receptor agonist nalbuphine in rhesus monkeys [65] as well as mu opioid receptor agonist-mediated antinociception in rhesus monkeys [65], rats [66], and mice [67, 68]. Accordingly, an increase in D2/D3 receptor density should result in an increased sensitivity to stimuli that enhance dopamine in the accumbens (but see $[69,70]$ who, surprisingly, found a negative correlation between D2 receptor levels in the striatum and reports of "drug liking" for or positive and negative effects of psychostimulants).

Pharmacology 2017;100:50-63 DOI: $10.1159 / 000475600$ 
The only robust, that is, consistent across-species finding, namely, that accumbal D2/D3 receptor density/ availability increased upon power wielding was, however, not correlated with consistent effects on measures of dopamine sensitivity when using cocaine as a pharmacologic probe and i.v. cocaine self-administration [3, $11,71]$ as a behavioral readout (as would be expected from pharmacologic principle, see above): dominant male cynomolgous monkeys sometimes show decreased [72] or increased [49] responding (i.e., "worked less hard or harder") for at least some of the available cocaine doses than their subordinate conspecifics, even if tested by the same laboratory that also found that dominance in female monkeys increased responding for i.v. cocaine [8]. Power wielding also increased responses to cocaine in male Lister hooded rats [11]. Of note, all these i.v. cocaine self-administration data were obtained once responding for cocaine became stable, that is, once power wielding-associated changes were reflected during the maintenance phase (as opposed to the acquisition phase of either dominance or cocaine self-administration, but see [8] for a different interpretation). Finally, response rate data obtained under the fixed-ratio schedules of reinforcement employed in the abovequoted experiments are extremely difficult to interpret due to the direct drug effect during the session (drug satiation, direct effects on motor behavior), especially if the drug under investigation is cocaine, that is, a drug of abuse that possesses aversive effects at the very same doses that are attractive for a cocaine consumer [21, 64]. For different interpretations of the quoted experimental findings, the reader is referred to the respective original publications.

\section{Effects of Subordination on the Sensitivity to Psychostimulant Stimuli: Human and Animal Experimental Data}

There are a number of studies (reviewed by [73]) demonstrating that an extreme form of subordination/submission, that is, social defeat, sensitizes the defeated animals to the locomotor and rewarding effects of psychostimulants, while reducing their self-administration. "Social submission is a known risk trait for drug abuse in laboratory animals" (p. 279 in [73]). The reader is also referred to the excellent work of Russo et al. [74-76] and Miczek et al. [77].

We are not aware of any study on human primates that investigated the effects of power wielding on the subordi- nate under controlled experimental conditions. Epidemiologic studies and meta-analyses often, although not consistently, demonstrate an inverse correlation between socioeconomic status (SES) and consumption of illicit drugs and alcohol (see, e.g., [78-80]) including the use of cocaine $[81,82]$.

\section{Effects of Psychostimulant Consumption on the Dopamine System}

If subordinate individuals are vulnerable to psychostimulant (i.e., cocaine or methamphetamine) abuse and dependence, as the abovementioned data show, what are the consequences of psychostimulant abuse on the dopamine system and, hence, to the sensitivity of a subordinate and psychostimulant abusing individual? When compared to normal controls, humans who had abused cocaine for at least 6 months at a rate of at least a self-estimated " 4 g" per week showed a $-14 \%$ decrease in dopamine $\mathrm{D} 2$ receptor availability in their basal ganglia, which persisted 3-4 months after detoxification, the D2 receptor availability being negatively correlated with depressive symptoms as assessed with the Beck Depression Inventory [83]. Dysphoria and other depression-like symptoms are well known in psychostimulant withdrawal [25].

\section{Neural Working Model of PAD}

If, as detailed above, power wielding increases D2/D3 receptor availability, thus most likely increasing the sensitivity for rewarding stimuli, whereas subordination decreases D2/D3 receptor availability and whereas psychostimulant abuse itself decreases D2/3 receptor availability, then power-wielding individuals should be protected against dependence syndromes. Why then does power wielding seem to be a stimulus that has abuse liability, that is, why does power wielding carry the risk of rendering susceptive individuals dependent on it, resulting in $\mathrm{PAD}$ ?

Our neural working model of PAD (Fig. 1) tries to reconcile these seemingly discrepant findings. From the psychotherapeutic perspective, it is very plausible that a power wielder has to fear her/his loss of power because social circumstances render this likely and/or because the power wielder's fear is unrealistically enhanced due to her/his psychopathology. In our model, loss of power constitutes withdrawal, that is, ICD10 criterion \#3. Interestingly, the Addiction Research Center Inventory (ARCI), a ques-
56

Pharmacology 2017;100:50-63

DOI: $10.1159 / 000475600$
Zernig/Hiemke 
Fig. 1. Neural working model of power abuse disorder (PAD). Shown is the progression from the use of power that is beneficial for both the socially dominant and subordinate partner in a power dyad to $\mathrm{PAD}$, which is harmful for both.

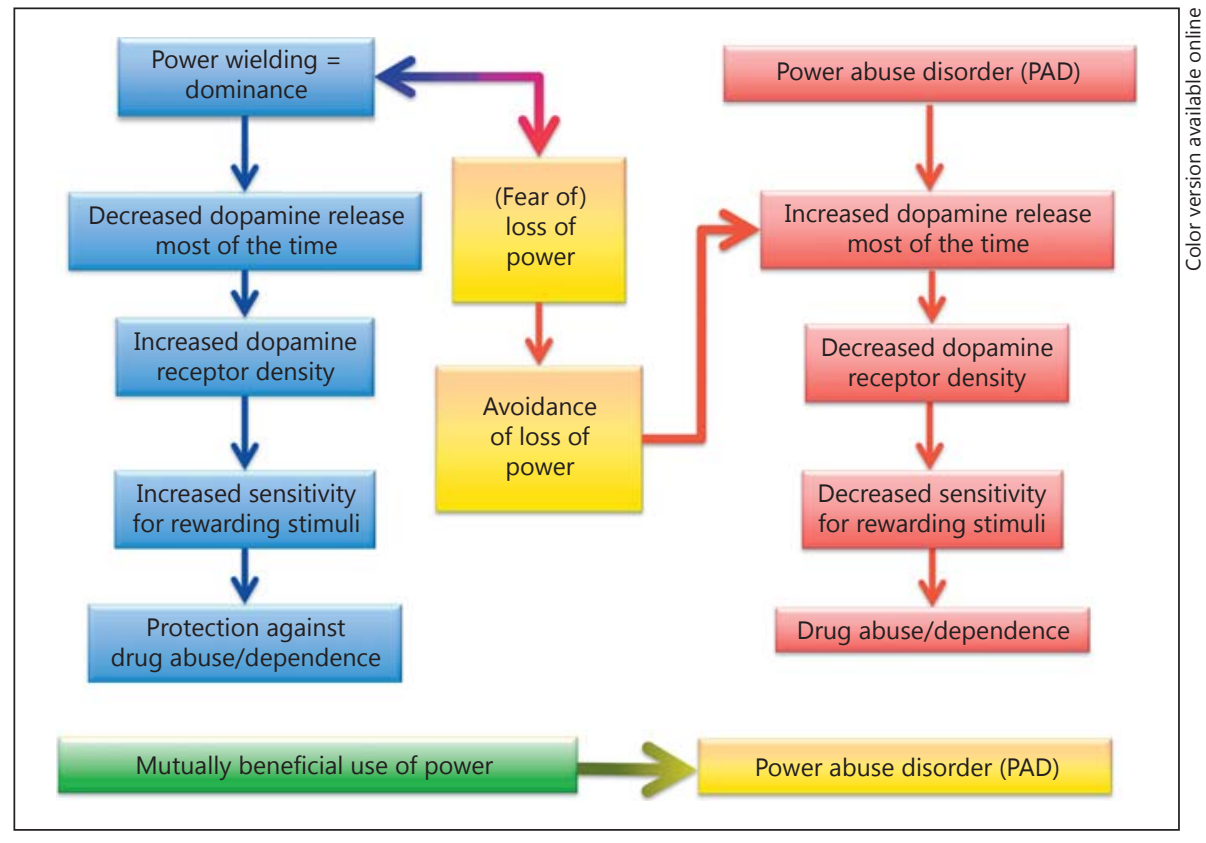

tionnaire published as early as 1963 and based on selfreports of drug users [84], lists the statement "I fear that I will lose the contentment that I have now" in the Morphine Benzedrine Group (Benzedrine ${ }^{\circledR}$ was a trade name for amphetamine). Similarly, when cocaine-dependent subjects received an infusion of $0.6 \mathrm{mg} / \mathrm{kg}$ i.v. cocaine over $30 \mathrm{~s}$, after around $15 \mathrm{~min}$, self-ratings of "low" and "craving" already reached a maximum when the "high" score had declined from its maximum but was still halfmaximal (see Figure 2 of [18]). Thus, the fear of the approaching termination of the addictive stimulus is known to produce intense - and highly motivational - feelings in drug abusers. The same is to be expected from power abusers, as illustrated by a vast number of historic accounts of "paranoid tendencies" in despotic rulers in a number of different cultures.

Thus, the anticipated loss of power is expected to stimulate the power wielder's motivational neuronetworks, with increased accumbal dopamine as the major neurochemical correlate. The dopamine release induced by anticipation/fear and the resulting avoidance behavior, in turn, leads to a decrease in available D2/D3 receptors. Once this occurs, the power wielder is caught in an oscillation between (1) a state in which he/she finds him/ herself under the influence of an increased dopaminergic tone most of the time, which decreases his/her DA receptor sensitivity (by the downregulation of receptor density and/or decrease in signal transduction efficacy (loss of power), and (2) a state in which dopamine may

Power Abuse Disorder be transiently (phasically) increased during power wielding but remains lower for most of the time, upregulating DA receptors and/or increasing signal transduction efficacy. Once the balance between the 2 states tips in favor of state (1), a downward spiral can result that is very similar to the allostasis model proposed for drug abuse ([19], compared to other models of addiction in [21]): as PAD progresses, the initial D2/D3 receptor sensitivity is never obtained again, resulting in the fulfillment of the well-known dependence syndrome diagnostic criteria of withdrawal (ICD10 criterion \#3; [24]) and neglect of alternative stimuli (ICD10 criterion \#5), which in the case of PAD would be all non-power stimuli. Our working model (Fig. 1) predicts that all drugs of abuse that are powerful dopamine releasers, that is, psychostimulants, remain the most attractive pharmacologic class of drugs of abuse for PADed individuals, especially if their imagined or real loss of power occurs at a time when their own dopamine resources are depleted, providing a much desired boost to a flagging motivated behavioral output.

\section{Zeitgeist Diagnosis "Burnout" May Very Likely Hide PADed Individuals}

As described above, many PADed individuals are expected to hide symptoms that they believe may be perceived as "weakness" and thus may threaten their pow-

Pharmacology 2017;100:50-63 57 
erful position. On the other hand, the Zeitgeist diagnosis of "burnout" or "burn out" (no separate diagnosis in the DSM5 yet, and listed under ICD10 code Z73) may offer PADed individuals a socially sanctioned diagnosis. The term "burnout" itself evokes the image of exhausted resources (i.e., low dopamine levels and/or a decreased signal transduction in the dopamine system, as suggested in the present article). Of note, most of the 9 symptoms of the subscale "emotional exhaustion" of the widely used Maslach Burnout Inventory (MBI) [33], that is, "I feel emotionally drained from my work," "I feel used up at the end of the workday," "I feel fatigued when I get up in the morning and have to face another day on the job," "working with people all day is really a strain for me," "I feel burned out from my work," "I feel frustrated by my job," "I feel I am working too hard on my job," "working with people directly puts too much stress on me," and "I feel like I am at the end of my rope" bear a striking resemblance to some symptoms experienced during stimulant withdrawal, that is, fatigue, hypersomnia, and psychomotor retardation, all of which are plausibly due to an exhaustion of the dopamine system (withdrawal generally carries the DSM5 code 292.0, without a specifier for (psycho)stimulant withdrawal; however, psychostimulant withdrawal symptoms are described in detail on p. 569 of [25]). Please keep in mind that we think that PAD is associated with an overstimulation of the dopaminergic system (Fig. 1) that leads to its exhaustion, thus producing symptoms that are due to psychostimulant (i.e., dopamine releaser) withdrawal. Interestingly, 2 burnout studies found that individuals who were hierarchically higher suffered more from these exhaustion symptoms than their lower-ranking coworkers within the same workplace, that is, Swiss industries of various sizes [34] or the Bavarian school system [35]. The researchers of the Swiss sample described this as a "reversed social gradient." In the Bavarian sample, a social bias toward overdiagnosing and overtreating the surveyed school principals as opposed to their lower ranking teaching staff seems unlikely, because in our opinion even "simple" Bavarian teachers (and not only principals) enjoy globally outstanding social security. A survey of anesthesiology chairpersons in the United States [36] found that $28 \%$ (i.e., 26 of 93 ) chairpersons met the criteria for high burnout and an additional 31\% met the criteria for moderately high burnout. Among the aggravating issues reported by the chairpersons [36] were "faculty retention" (indicating power struggles) and "problems with departmental budget" (again, a power related is- sue). Unfortunately, this study did not compare chairpersons to hierarchically lower personnel.

One burnout study found a higher rate of burnout in intermediate (as opposed to high or low) management positions [37], reflecting, in our opinion, the 2-sided power struggle of a "hierarchically sandwiched" individual. Accordingly, a Swedish study [39] found the smallest incidence of burnout in business owners (as opposed to white- and blue collar workers in companies), a finding that we would explain by the hierarchically supreme position of a business owner. Apparently, the financial stress of business owners seemed to impact on their incidence of burnout less than power struggles in companies [39]. In a similar vein, decision latitude, which increases with an increase in the hierarchic position within an institution, inversely correlated with burnout symptoms in a study of English civil servants (the so-called Whitehall II study, [38]). Subjective SES was also inversely correlated with burnout severity in an Israeli sample of longterm health care staff members [40]. Of great interest, the authors of a study of Finnish dentist - dental nurse dyads [41] suggest that the - hierarchically higher - dentist "passes exhaustion" to the nurse, another plausible reason why many humans are known to seek a hierarchically superior position in a group of conspecifics. To summarize, individuals in higher hierarchical positions report, to a large degree, burnout symptoms that we think can also be found in PADed individuals, with 2 studies [34, 35] reporting a higher percentage of burned out individuals in higher hierarchical positions than in lower hierarchical positions within the same work environment.

We therefore think that the Zeitgeist diagnosis "burnout" covers, at least in the MBI subscale "emotional exhaustion," symptoms that are a result of PAD. In PADed individuals, "burnout" can thus be considered a secondary diagnosis based on symptoms that are better explained and treated by correctly allocating them to PAD. To paraphrase, many PADed individuals may hide or may be misdiagnosed and suboptimally treated under the socially sanctioned diagnosis "burnout."

\section{Future Clinical Research}

We think it extremely worthwhile to investigate the clinical presentation of PAD and its neurobiologic correlates and to investigate if PAD is comorbid with psychostimulant use disorder, as the present article suggests. However, we opine that any scientific study systematically investigating the drug abuse patterns of
58

Pharmacology 2017;100:50-63

DOI: $10.1159 / 000475600$
Zernig/Hiemke 
high-ranking individuals in hierarchic structures (e.g., the military, churches, political systems, businesses) would be extremely difficult to perform because (1) a PADed individual would not seek treatment during power wielding and (2) would likely be extremely reluctant to seek psychiatric/psychotherapeutic/psychologic help because of the social stigma of a diagnosis of a mental disorder that most likely is even more punitive for a high-ranking individual than a subordinate one (see also above). Most likely, PADed individuals of middle to lower ranks would seek therapeutic help during phases of foreseen, imagined and/or real loss of power, complaining about "burnout" (detailed above), "mobbing," "bossing," or presenting with depressive symptoms or conversion (psychosomatic) symptoms. We also think that these coping mechanisms are the reason why there is essentially no published clinical evidence on PAD.

A plethora of other questions have to be addressed with respect to the diagnosis, epidemiology, and comorbidity of PAD. The following questions are but a tiny sample: What is the prevalence and incidence of PAD in the general population? Is PAD prevalence and/or incidence proportional to the hierarchic position in a social system of interest, that is, is obtaining a higher hierarchic position the result of an underlying PAD or constitutes a higher hierarchic position an increased risk of developing $\mathrm{PAD}$ ? In which ways do subpopulations or subcultures or various political systems differ with respect to the prevalence of PAD? Which mental disorders other than substance-use disorders is PAD comorbid with?

\section{Possible Pharmacotherapeutic Approaches to Treat PAD}

If, as discussed above, PAD is associated with a dysfunction of the mesocorticolimbic dopaminergic system, then medications that stabilize this system may be useful for the treatment of PAD. On pharmacologic principle, stabilization of a dysregulated (i.e., oscillating) dopaminergic system (with power craving associated with a hypodomanigergic state and power wielding associated with a hyperdopaminergic state, see above) could be a obtained with the partial dopamine D2 receptor agonist aripiprazole, which has proven efficacious in the treatment and prophylaxis of manic episodes in bipolar patients $[85,86]$ ((http://www.awmf.org/leitlinien/detail/1l/038-019. html). However, according to these reviews and guidelines, aripiprazole did not significantly improve depres-

Power Abuse Disorder sive episodes in bipolar patients and resulted in extrapyramidal effects, akathisia in particular.

For hypodopaminergic episodes in the course of PAD, the dopamine transport inhibitor bupropion [87] may be effective. Bupropion is registered in some countries both as an antidepressant and as a smoking cessation aid [88]. Effective antidepressant plasma levels for bupropion and its active metabolite hydroxybupropion have been established $[89,90]$. However, precisely because of its psychostimulant-like molecular target, neurochemic effects, and behavioral experimental effects (reviewed in [91]), bupropion possesses abuse liability for some patients [91, 92]. In that respect, and on the same pharmacologic principle, bupropion shares the fate of other substitution (maintenance) medications used for the treatment of cocaine-dependence syndromes $[93,94]$ and opioid-dependence syndromes [95-98]. Therefore, antidepressants without evidence of abuse liability despite widespread and long therapeutic use may be more safely used to treat the depressive symptoms of PAD.

\section{Future Basic Research}

As detailed above, the experimental evidence obtained so far $[3,8,11]$ suggests that power wielding (social dominance) is associated with an increase in accumbal D2/D3 receptor density. In cynomolgous monkeys, it was shown that this increase in D2/D3 receptor density is a consequence of achieving power and not a trait of powerful individuals. Respective data in male and female rats or mice are still lacking, with the mouse being an especially important experimental genus due to the plethora of transgenic models available in mice $[10,99]$. The most striking apparent discrepancy so far is that male and female individuals, despite showing the same increase in D2/D3 receptor availability, show an apparently opposite pattern of i.v. cocaine self-administration obtained by the same group using the same schedule of reinforcement [3, 8]. This apparent discrepancy needs to be resolved, again preferably in a widely accessible experimental species/genus (mouse and/or rat), and by quantifying cocaine reinforcement/reward in operant schedules of reinforcement that (1) optimally, avoid direct drug effects on responding, that is, second-order schedules of reinforcement with the cocaine stimulus delivered at the end of the session, or (2) at least, minimize a direct drug effect on responding, that is, progressive ratios of reinforcement (for detailed methodological discussions see, e.g., $[21,64]$ ) and are complemented by rate-free measures of drug reward/

Pharmacology 2017;100:50-63

DOI: $10.1159 / 000475600$ 
aversion, for example, $\mathrm{CPP} /$ conditioned place avoidance (CPP/CPA; see, e.g., $[10,100,101])$. Cocaine as (1) a dopamine transport inhibitor and, hence, an enhancer of extracellular dopamine in mesocorticolimbic brain regions, as well as (2) a drug of abuse with high abuse liability, seems an excellent tool to test (a) the consequences of the well-documented dominance-induced increase in D2/D3 receptors in reward neuronetworks with respect to the sensitivity of the power-wielding individual to reward in general and (b) with respect to the increased risk of PADed individuals for cocaine dependence, a comorbidity that seems well known anecdotally and which the findings in female cynomolgous monkeys [8] and male Lister Hooded rats [11] seem to support. Nader and coworkers have already contributed a great deal of data obtained in a food-cocaine choice experimental paradigm suggesting, in our interpretation, that, overall, the sensitivity to physiological stimuli (i.e., palatable food pellets) is not changed by the acquisition of power/social dominance $[8,71,102]$. Respective data obtained from widely used and easily accessible experimental paradigms and species (e.g., CPP/CPA in C57BL/6J mice or Sprague Dawley rats) would be desirable. Concurrent CPP paradigms (see, e.g., $[99,103]$ ) could allow a direct comparison with the monkey food-cocaine choice data described above. As already stated in the introduction, animal models that operationalize a power struggle [1-10] with opposite consequences for the participants (i.e., winning/ losing a fight) constitute a sound and well-validated animal experimental basis to study PAD. As stated above, research has focused exclusively on the subordinate/loser of such a fight. By singling out individuals with an ex- treme degree of power wielding under these controlled experimental conditions (with measures of situation-inappropriate power wielding to be developed by the field) and making them the focus of investigation, a lot could be learned about the neural correlates of PAD.

\section{Conclusions}

In conclusion, we have tried to establish the case that power wielding is a stimulus that may be of considerable abuse liability in some individuals. The resulting PAD can be considered a nondrug form of a dependence syndrome, sharing neuronetworks and pathophysiology with substance-use disorders/drug dependence. In this article, research avenues have been suggested to increase our understanding of PAD in an effort to help the victims of PADed individuals to overcome this socially harmful disorder and the PADed individuals themselves.

\section{Acknowledgments}

This work was supported by the Austrian Science Fund grant P26248 and by the Society for the scientific Investigation of Power AbuseDisorder(GesellschaftzurwissenschaftlichenUntersuchung der Machtmissbrauchsstoerung; gwm = sipad).

\section{Disclosure Statement}

The authors declare that the research was conducted in the absence of any commercial or financial relationships that could be construed as a potential conflict of interest.

\section{References}

1 Kudryavtseva NN, Madorskaya IA, Bakshtanovskaya IV: Social success and voluntary ethanol consumption in mice of C57BL/6J and CBA/Lac strains. Physiol Behav 1991;50: 143-146.

2 Tidey JW, Miczek KA: Social defeat stress selectively alters mesocorticolimbic dopamine release: an in vivo microdialysis study. Brain Res 1996;721:140-149.

3 Morgan D, Grant KA, Gage HD, Mach RH, Kaplan JR, Prioleau O, Nader SH, Buchheimer N, Ehrenkaufer RL, Nader MA: Social dominance in monkeys: dopamine D2 receptors and cocaine self-administration. Nat Neurosci 2002;5:169-174.

4 Lucas LR, Celen Z, Tamashiro KL, Blanchard RJ, Blanchard DC, Markham C, Sakai RR, McEwen BS: Repeated exposure to social stress has long-term effects on indirect mark- ers of dopaminergic activity in brain regions associated with motivated behavior. Neuroscience 2004;124:449-457.

5 Austin PJ, Beyer K, Bembrick AL, Keay KA: Peripheral nerve injury differentially regulates dopaminergic pathways in the nucleus accumbens of rats with either 'pain alone' or 'pain and disability'. Neuroscience 2010;171: 329-343.

6 Fuxjager MJ, Forbes-Lorman RM, Coss DJ, Auger CJ, Auger AP, Marler CA: Winning territorial disputes selectively enhances androgen sensitivity in neural pathways related to motivation and social aggression. Proc Natl Acad Sci U S A 2010;107:1239312398.

7 Veyrac A, Wang G, Baum MJ, Bakker J: The main and accessory olfactory systems of female mice are activated differentially by dom- inant versus subordinate male urinary odors. Brain Res 2011;1402:20-29.

8 Nader MA, Nader SH, Czoty PW, Riddick NV, Gage HD, Gould RW, Blaylock BL, Kaplan JR, Garg PK, Davies HM, Morton D, Garg S, Reboussin BA: Social dominance in female monkeys: dopamine receptor function and cocaine reinforcement. Biol Psychiatry 2012;72:414-421.

9 Georgiev AV, Klimczuk AC, Traficonte DM, Maestripieri D: When violence pays: a costbenefit analysis of aggressive behavior in animals and humans. Evol Psychol 2013;11:678699.

10 Zernig G, Pinheiro BS: Dyadic social interaction inhibits cocaine-conditioned place preference and the associated activation of the accumbens corridor. Behav Pharmacol 2015;26: 580-594. 
11 Jupp B, Murray JE, Jordan ER, Xia J, Fluharty M, Shrestha S, Robbins TW, Dalley JW: Social dominance in rats: effects on cocaine self-administration, novelty reactivity and dopamine receptor binding and content in the striatum. Psychopharmacology (Berl) 2016;233: 579-589.

12 Fantin G, Bottecchia D: Effect of nucleus accumbens destruction in rat. Experientia 1984; 40:573-575.

13 Wasser SK, Norton GW, Rhine RJ, Klein N, Kleindorfer S: Ageing and social rank effects on the reproductive system of free-ranging yellow baboons (Papio cynocephalus) at Mikumi National Park, Tanzania. Hum Reprod Update 1998;4:430-438.

14 Maestripieri D, Georgiev AV: What cortisol can tell us about the costs of sociality and reproduction among free-ranging rhesus macaque females on Cayo Santiago. Am J Primatol 2016;78:92-105.

15 Erk S, Spitzer M, Wunderlich AP, Galley L, Walter H: Cultural objects modulate reward circuitry. Neuroreport 2002;13:24992503.

16 Knutson B, Taylor J, Kaufman M, Peterson R, Glover G: Distributed neural representation of expected value. J Neurosci 2005;25:48064812.

17 Imperato A, Di Chiara G: Preferential stimulation of dopamine release in the nucleus accumbens of freely moving rats by ethanol. J Pharmacol Exp Ther 1986;239:219-228.

18 Breiter HC, Gollub RL, Weisskoff RM, Kennedy DN, Makris N, Berke JD, Goodman JM, Kantor HL, Gastfriend DR, Riorden JP, Mathew RT, Rosen BR, Hyman SE: Acute effects of cocaine on human brain activity and emotion. Neuron 1997;19:591-611.

19 Ahmed SH, Koob GF: Transition from moderate to excessive drug intake: change in hedonic set point. Science 1998;282:298-300.

20 Lenoir M, Serre F, Cantin L, Ahmed SH: Intense sweetness surpasses cocaine reward. PLoS One 2007;2:e698.

21 Zernig G, Ahmed SH, Cardinal RN, Morgan D, Acquas E, Foltin RW, Vezina P, Negus SS, Crespo JA, Stöckl P, Grubinger P, Madlung E, Haring C, Kurz M, Saria A: Explaining the escalation of drug use in substance dependence: models and appropriate animal laboratory tests. Pharmacology 2007;80:65119.

22 Haber SN, Knutson B: The reward circuit: linking primate anatomy and human imaging. Neuropsychopharmacology 2010;35:426.

23 Salamone JD, Correa M: The mysterious motivational functions of mesolimbic dopamine. Neuron 2012;76:470-485.

24 WHO: Tenth Revision of the International Classification of Diseases (ICD-10). Geneva, World Health Organisation, 1992.

25 APA: Diagnostic and Statistical Manual of Mental Disorders (DSM-5(R)). Washington, American Psychiatric Association, 2013.
26 van den Brink W: Evidence-based pharmacological treatment of substance use disorders and pathological gambling. Curr Drug Abuse Rev 2012;5:3-31.

27 Castro DC, Cole SL, Berridge KC: Lateral hypothalamus, nucleus accumbens, and ventral pallidum roles in eating and hunger: interactions between homeostatic and reward circuitry. Front Syst Neurosci 2015;9:90.

28 Prast JM, Schardl A, Schwarzer C, Dechant G, Saria A, Zernig G: Reacquisition of cocaine conditioned place preference and its inhibition by previous social interaction preferentially affect D1-medium spiny neurons in the accumbens corridor. Front Behav Neurosci 2014;8:317.

29 Prast JM, Schardl A, Sartori SB, Singewald N, Saria A, Zernig G: Increased conditioned place preference for cocaine in high anxiety related behavior $(\mathrm{HAB})$ mice is associated with an increased activation in the accumbens corridor. Front Behav Neurosci 2014;8:441.

30 Kummer K, Klement S, Eggart V, Mayr MJ, Saria A, Zernig G: Conditioned place preference for social interaction in rats: contribution of sensory components. Front Behav Neurosci 2011;5:80.

31 Sapolsky RM: The influence of social hierarchy on primate health. Science $2005 ; 308$ :648652.

32 Sapolsky RM, Share LJ: A pacific culture among wild baboons: its emergence and transmission. PLoS Biol 2004;2:E106.

33 Maslach C, Jackson SE: The measurement of experienced burnout. J Occup Behav 1981;2: 99-113.

34 Hämmig O, Bauer GF: The social gradient in work and health: a cross-sectional study exploring the relationship between working conditions and health inequalities. BMC Public Health 2013;13:1170.

35 Weber A, Weltle D, Lederer P: Ill health and early retirement among school principals in Bavaria. Int Arch Occup Environ Health 2005;78:325-331.

36 De Oliveira GS Jr, Ahmad S, Stock MC, Harter RL, Almeida MD, Fitzgerald PC, McCarthy RJ: High incidence of burnout in academic chairpersons of anesthesiology: should we be taking better care of our leaders? Anesthesiology 2011;114:181-193.

37 Metlaine A, Sauvet F, Gomez-Merino D, Elbaz M, Delafosse JY, Leger D, Chennaoui M: Association between insomnia symptoms, job strain and burnout syndrome: a cross-sectional survey of 1300 financial workers. BMJ Open 2017;7:e012816.

38 Kuper H, Marmot M: Job strain, job demands, decision latitude, and risk of coronary heart disease within the Whitehall II study. J Epidemiol Community Health 2003;57:147-153.

39 Soares JJ, Grossi G, Sundin O: Burnout among women: associations with demographic/socioeconomic, work, life-style and health factors. Arch Womens Ment Health 2007;10:61-71.

40 Ayalon L: Subjective socioeconomic status as a predictor of long-term care staff burnout and positive caregiving experiences. Int Psychogeriatr 2008;20:521-537.

41 Hakanen JJ, Perhoniemi R, Bakker AB: Crossover of exhaustion between dentists and dental nurses. Stress Health 2014;30:110-121.

42 Li J: Karoshi: an international work-related hazard? Int J Cardiol 2016;206:139-140.

43 Yamauchi T, Yoshikawa T, Takamoto M, Sasaki T, Matsumoto S, Kayashima K, Takeshima T, Takahashi M: Overwork-related disorders in Japan: recent trends and development of a national policy to promote preventive measures. Ind Health 2017, Epub ahead of print.

44 Gurman AS, Messer SB: Essential Psychotherapies. Theory and Practice. New York, Guilford Press, 1995.

45 Zernig G, Wallner R, Grohs U, Kriechbaum N, Kemmler G, Saria A: A randomized trial of short psychotherapy versus sustained-release bupropion for smoking cessation. Addiction 2008;103:2024-2031.

46 Zernig G: Replication and further scientific investigations will tell the truth. Addiction 2008;103:2033-2034.

47 Winger G, Hofmann FG, Woods JH: A Handbook on Drug and Alcohol Abuse. New York, Oxford University Press, 1992.

48 Gore RK, Webb TS, Hermes ED: Fatigue and stimulant use in military fighter aircrew during combat operations. Aviat Space Environ Med 2010;81:719-727.

49 Czoty PW, Morgan D, Shannon EE, Gage HD, Nader MA: Characterization of dopamine D1 and D2 receptor function in socially housed cynomolgus monkeys self-administering cocaine. Psychopharmacology (Berl) 2004;174:381-388.

50 Di Chiara G, Imperato A: Preferential stimulation of dopamine release in the nucleus accumbens by opiates, alcohol, and barbiturates: studies with transcerebral dialysis in freely moving rats. Ann N Y Acad Sci 1986; 473:367-381.

51 Hamid AA, Pettibone JR, Mabrouk OS, Hetrick VL, Schmidt R, Vander Weele CM, Kennedy RT, Aragona BJ, Berke JD: Mesolimbic dopamine signals the value of work. Nat Neurosci 2016;19:117-126.

52 du Hoffmann J, Nicola SM: Dopamine invigorates reward seeking by promoting cueevoked excitation in the nucleus accumbens. J Neurosci 2014;34:14349-14364.

53 Calipari ES, Bagot RC, Purushothaman I, Davidson TJ, Yorgason JT, Peña CJ, Walker DM, Pirpinias ST, Guise KG, Ramakrishnan C, Deisseroth K, Nestler EJ: In vivo imaging identifies temporal signature of D1 and D2 medium spiny neurons in cocaine reward. Proc Natl Acad Sci U S A 2016;113:2726-2731.

54 Howe MW, Dombeck DA: Rapid signalling in distinct dopaminergic axons during locomotion and reward. Nature 2016;535:505-510.

55 Wilson C, Nomikos GG, Collu M, Fibiger HC: Dopaminergic correlates of motivated behavior: importance of drive. J Neurosci 1995; 15(7 pt 2):5169-5178. 
56 Joseph MH, Datla K, Young AM: The interpretation of the measurement of nucleus accumbens dopamine by in vivo dialysis: the kick, the craving or the cognition? Neurosci Biobehav Rev 2003;27:527-541.

57 Bromberg-Martin ES, Matsumoto M, Hikosaka O: Dopamine in motivational control: rewarding, aversive, and alerting. Neuron 2010;68:815-834.

58 Kravitz AV, Tye LD, Kreitzer AC: Distinct roles for direct and indirect pathway striatal neurons in reinforcement. Nat Neurosci 2012;15:816-818.

59 Lobo MK, Covington HE 3rd, Chaudhury D, Friedman AK, Sun H, Damez-Werno D, Dietz DM, Zaman S, Koo JW, Kennedy PJ, Mouzon E, Mogri M, Neve RL, Deisseroth K, Han $\mathrm{MH}$, Nestler EJ: Cell type-specific loss of BDNF signaling mimics optogenetic control of cocaine reward. Science 2010;330:385-390.

60 Kenakin TP: Pharmacologic Analysis of Drug-Receptor Interaction, ed 2. New York, Raven Press, 1993.

61 Kenakin TP: A Pharmacology Primer. Theory, Applications, and Methods. Amsterdam, Elsevier, 2006.

62 Zernig G, Issaevitch T: Software for the Calculation of Agonist Efficacy and Apparent in vivo Affinity by Simultaneous Analysis of Several Dose-Response Curves. Champain, Wolfram Research Inc., 1995.

63 Zernig G, Issaevitch T, Woods JH: Calculation of agonist efficacy, apparent affinity, and receptor population changes after administration of insurmountable antagonists: comparison of different analytical approaches. J Pharmacol Toxicol Methods 1996;35:223-237.

64 Zernig G, Wakonigg G, Madlung E, Haring C, Saria A: Do vertical shifts in dose-response rate-relationships in operant conditioning procedures indicate "sensitization" to "drug wanting”? Psychopharmacology (Berl) 2004; 171:349-351.

65 Zernig G, Lewis JW, Woods JH: Clocinnamox inhibits the intravenous self-administration of opioid agonists in rhesus monkeys: comparison with effects on opioid agonist-mediated antinociception. Psychopharmacology (Berl) 1997;129:233-242.

66 Walker EA, Zernig G, Young AM: In vivo apparent affinity and efficacy estimates for mu opiates in a rat tail-withdrawal assay. Psychopharmacology (Berl) 1998;136:15-23.

67 Zernig G, Broadbear JH, Lewis JW, Brine GA, Woods JH: Opioid agonist effects on mouse writhing after irreversible mu receptor blockade with clocinnamox. Exp Clin Psychopharmacol 1995;3:323-329.

68 Zernig G, Burke T, Lewis JW, Woods JH: Mechanism of clocinnamox blockade of opioid receptors: evidence from in vitro and ex vivo binding and behavioral assays. J Pharmacol Exp Ther 1996;279:23-31.

69 Volkow ND, Wang GJ, Fowler JS, Logan J, Gatley SJ, Gifford A, Hitzemann R, Ding YS, Pappas N: Prediction of reinforcing responses to psychostimulants in humans by brain do- pamine D2 receptor levels. Am J Psychiatry 1999;156:1440-1443.

70 Volkow ND, Wang GJ, Fowler JS, Thanos PP, Logan J, Gatley SJ, Gifford A, Ding YS, Wong C, Pappas N: Brain DA D2 receptors predict reinforcing effects of stimulants in humans: replication study. Synapse 2002;46:79-82.

71 Czoty PW, Nader MA: Effects of dopamine D2/D3 receptor ligands on food-cocaine choice in socially housed male cynomolgus monkeys. J Pharmacol Exp Ther 2013;344: 329-338.

72 Morgan D, Brebner K, Lynch WJ, Roberts DC: Increases in the reinforcing efficacy of cocaine after particular histories of reinforcement. Behav Pharmacol 2002;13:389396.

73 Bardo MT, Neisewander JL, Kelly TH: Individual differences and social influences on the neurobehavioral pharmacology of abused drugs. Pharmacol Rev 2013;65:255-290.

74 Russo SJ, Murrough JW, Han MH, Charney DS, Nestler EJ: Neurobiology of resilience. Nat Neurosci 2012;15:1475-1484.

75 Christoffel DJ, Golden SA, Dumitriu D, Robison AJ, Janssen WG, Ahn HF, Krishnan V, Reyes CM, Han MH, Ables JL, Eisch AJ, Dietz DM, Ferguson D, Neve RL, Greengard P, Kim Y, Morrison JH, Russo SJ: IkB kinase regulates social defeat stress-induced synaptic and behavioral plasticity. J Neurosci 2011;31:314321.

76 Golden SA, Christoffel DJ, Heshmati M, Hodes GE, Magida J, Davis K, Cahill ME, Dias C, Ribeiro E, Ables JL, Kennedy PJ, Robison AJ, Gonzalez-Maeso J, Neve RL, Turecki G, Ghose S, Tamminga CA, Russo SJ: Epigenetic regulation of RAC1 induces synaptic remodeling in stress disorders and depression. Nat Med 2013;19:337344.

77 Miczek KA, Yap JJ, Covington HE 3rd: Social stress, therapeutics and drug abuse: preclinical models of escalated and depressed intake. Pharmacol Ther 2008;120:102-128.

78 Lemstra M, Bennett NR, Neudorf C, Kunst A, Nannapaneni U, Warren LM, Kershaw T, Scott CR: A meta-analysis of marijuana and alcohol use by socio-economic status in adolescents aged $10-15$ years. Can J Public Health 2008;99:172-177.

79 Hasin DS, Grant BF: The National Epidemiologic Survey on Alcohol and Related Conditions (NESARC) Waves 1 and 2: review and summary of findings. Soc Psychiatry Psychiatr Epidemiol 2015;50:1609-1640.

80 Henkel D, Zemlin U: Social inequality and substance use and problematic gambling among adolescents and young adults: a review of epidemiological surveys in Germany. Curr Drug Abuse Rev 2016;9:26-48.

81 Palamar JJ, Davies S, Ompad DC, Cleland CM, Weitzman M: Powder cocaine and crack use in the United States: an examination of risk for arrest and socioeconomic disparities in use. Drug Alcohol Depend 2015;149:108116.
82 Daniel JZ, Hickman M, Macleod J, Wiles N, Lingford-Hughes A, Farrell M, Araya R, Skapinakis P, Haynes J, Lewis G: Is socioeconomic status in early life associated with drug use? A systematic review of the evidence. Drug Alcohol Rev 2009;28:142-153.

83 Volkow ND, Fowler JS, Wang GJ, Hitzemann R, Logan J, Schlyer DJ, Dewey SL, Wolf AP: Decreased dopamine D2 receptor availability is associated with reduced frontal metabolism in cocaine abusers. Synapse 1993;14:169-177.

84 Haertzen CA, Hill HE, Belleville RE: Development of the addiction research center inventory (ARCI): selection of items that are sensitive to the effects of various drugs. Psychopharmacologia 1963;4:155-166.

85 Brown R, Taylor MJ, Geddes J: Aripiprazole alone or in combination for acute mania. Cochrane Database Syst Rev 2013;12:CD005000.

86 Muneer A: The treatment of adult bipolar disorder with aripiprazole: a systematic review. Cureus 2016;8:e562.

87 Nomikos GG, Damsma G, Wenkstern D, Fibiger HC: Acute effects of bupropion on extracellular dopamine concentrations in rat striatum and nucleus accumbens studied by in vivo microdialysis. Neuropsychopharmacology 1989;2:273-279.

88 Dhillon S, Yang LP, Curran MP: Bupropion: a review of its use in the management of major depressive disorder. Drugs 2008;68:653689.

89 Hiemke C, Baumann P, Bergemann N, Conca A, Dietmaier O, Egberts K, Fric M, Gerlach M, Greiner C, Gründer G, Haen E, Havemann-Reinecke U, Jaquenoud Sirot E, Kirchherr H, Laux G, Lutz UC, Messer T, Müller MJ, Pfuhlmann B, Rambeck B, Riederer P, Schoppek B, Stingl J, Uhr M, Ulrich S, Waschgler R, Zernig G: AGNP consensus guidelines for therapeutic drug monitoring in psychiatry: update 2011. Pharmacopsychiatry 2011;44:195-235.

90 Hiemke C, Bergemann N, Broich K, Clement HW, Conca A, Deckert J, Dietmaier O, Domschke K, Eckermann G, Egberts K, Fric M, Gerlach M, Greiner C, Gründer G, Haen E, Havemann-Reinecke $U$, Janssen $G$, Jaquenoud Sirot E, Laux G, Messer T, Mossner R, Müller MJ, Paulzen M, Pfuhlmann B, Riederer P, Saria A, Schoppek B, Schwarz M, Stegmann B, Steimer W, Stingl J, Uhr M, Ulrich S, Unterecker S, Waschgler R, Zernig G, Zurek G, Baumann P: AGNP consensus guidelines for therapeutic drug monitoring in psychiatry and neurology: update 2017. Pharmacopsychiatry 2017; submitted.

91 Zernig G, De Wit H, Telser S, Nienhusmeier M, Wakonigg G, Sturm K, Berger I, Kemmler G, Saria A: Subjective effects of slow-release bupropion versus caffeine as determined in a quasi-naturalistic setting. Pharmacology 2004;70:206-215.

92 Langguth B, Hajak G, Landgrebe M, Unglaub W: Abuse potential of bupropion nasal insufflation: a case report. J Clin Psychopharmacol 2009;29:618-619. 
93 Mooney ME, Herin DV, Specker S, Babb D, Levin FR, Grabowski J: Pilot study of the effects of lisdexamfetamine on cocaine use: a randomized, double-blind, placebo-controlled trial. Drug Alcohol Depend 2015;153: 94-103.

94 Levin FR, Mariani JJ, Specker S, Mooney M, Mahony A, Brooks DJ, Babb D, Bai Y, Eberly LE, Nunes EV, Grabowski J: Extended-release mixed amphetamine salts vs placebo for comorbid adult attention-deficit/hyperactivity disorder and cocaine use disorder: a randomized clinical trial. JAMA Psychiatry 2015;72: 593-602.

95 Giacomuzzi S, Kemmler G, Ertl M, Riemer Y: Opioid addicts at admission vs. slow-release oral morphine, methadone, and sublingual buprenorphine maintenance treatment participants. Subst Use Misuse 2006;41:223244.
96 Farrell M, Wodak A, Gowing L: Maintenance drugs to treat opioid dependence. BMJ 2012; 344:e2823.

97 Ferri M, Minozzi S, Bo A, Amato L: Slow-release oral morphine as maintenance therapy for opioid dependence. Cochrane Database Syst Rev 2013;6:CD009879.

98 Nielsen S, Larance B, Degenhardt L, Gowing L, Kehler C, Lintzeris N: Opioid agonist treatment for pharmaceutical opioid dependent people. Cochrane Database Syst Rev 2016; 5:CD011117.

99 Zernig G, Kummer KK, Prast JM: Dyadic social interaction as an alternative reward to cocaine. Front Psychiatry 2013;4:100.
100 Bardo MT, Bevins RA: Conditioned place preference: what does it add to our preclinical understanding of drug reward? Psychopharmacology (Berl) 2000;153:31-43.

101 Tzschentke TM: Measuring reward with the conditioned place preference (CPP) paradigm: update of the last decade. Addict Biol 2007;12:227-462.

102 Czoty PW, Nader MA: Effects of oral and intravenous administration of buspirone on food-cocaine choice in socially housed male cynomolgus monkeys. Neuropsychopharmacology 2015;40:1072-1083.

103 Fritz M, El Rawas R, Klement S, Kummer K, Mayr MJ, Eggart V, Salti A, Bardo MT, Saria A, Zernig G: Differential effects of accumbens core vs shell lesion in a rat concurrent conditioned place preference paradigm for cocaine vs social interaction. PLoS One 2011;6:e26761. 